\title{
A Study on Histopathological Association of Endometrial Hyperplasia with Estrogen Receptor, Progesterone Receptor Status
}

\section{Siva Kaliyamoorthy ${ }^{1,2}$, Varadharajaperumal Radhakrishnan ${ }^{1}$, Mutharasu Arasu² and Jawahar Ramasamy ${ }^{1 *}$}

${ }^{1}$ Associate Professor, Department of Pathology, Aarupadai Veedu Medical College and Hospital, Vinayaka Mission's Research Foundation (Deemed to be university), Kirumampakkam Puducherry, India

${ }^{2}$ Associate Professor, Department of Pathology, Sri Manakula Vinayagar Medical College and Hospital, Puducherry

*Corresponding Author: Jawahar Ramasamy, Professor, Department of Pathology, Aarupadai Veedu Medical College and Hospital, Vinayaka Mission's Research Foundation (Deemed to be university), Kirumampakkam Puducherry, India.
Received: November 01, 2021

Published: December 21, 2021

(C) All rights are reserved by Jawahar

Ramasamy., et al.

\begin{abstract}
Endometrial hyperplasia is defined as an abnormal proliferation of the endometrium with increased gland to stroma ratio and abnormalities in epithelial cells linked to prolonged exposure to estrogen stimulation. Endometrial curettings and hysterectomy specimens diagnosed with Endometrial Hyperplasia cases diagnosed with histopathologically were subjected to Immunohistochemical examination for Estrogen and Progesterone receptor status using DAKO monoclonal Estrogen Receptor (ER) and Progesterone Receptor (PR) antibody kit. A semiquantitative scoring system (H score system) has employed and a composite score of grade of intensity and percentage of stained cells. Most of the cases received and taken up for study belonged to the Reproductive age group of 18-46. The commonest clinical diagnosis of these cases was Dysfunctional uterine bleeding. Simple hyperplasia without atypia (SH) was found to be the commonest histopathological diagnosis in patients with Dysfunctional uterine bleeding. H scores of ER and PR in the glandular epithelial cells of these cases was showed PR scores being higher than ER in cases of SH. With the advent of newer hormonal therapies which can prove beneficial in avoiding surgical management, knowing the status of estrogen and progesterone receptors in the hyperplastic endometrium can prove a better therapeutic option compared to hysterectomy. Hormonal therapy using progestins can be tried before surgical management in patients with endometrial hyperplasia because the receptor status is favorable.
\end{abstract}

Keywords: Endometrial Hyperplasia; Estrogen Receptor; Progesterone Receptor; Dysfunctional Uterine Bleeding

\section{Introduction}

Endometrium undergoes a variety of cyclical changes in the morphology from proliferation to differentiation and finally shed under the influence of hormones mainly estrogen and progesterone [1] RRobbins, $2010 \# 7\}$. These hormones are in turn regulated by hormones of the pituitary gland like follicle stimulating hormone (FSH) and luteinizing hormone (LH) only to repeat these changes cyclically. Together the hypothalamic, pituitary and ovar- ian factors and their interactions regulate the maturation of ovarian follicles, ovulation, and menstruation [2]. Such a dynamic tissue was influenced by hormones is prone to develop an abnormality such as endometrial hyperplasia. Endometrial hyperplasia is defined as an abnormal proliferation of the endometrium with increased gland to stroma ratio and abnormalities in epithelial cells linked to prolonged exposure to estrogen stimulation [1]. In this new era of nuclear families with more and more women opting for 
lesser parity and oral contraceptives the risk of prolonged estrogen exposure has increased twofold. Hence the incidence of menorrhagia and dysfunctional uterine bleeding, the clinical manifestation of endometrial hyperplasia commonly found in women in the perimenopausal age group is on the rise even in younger women of the reproductive age group [3].

It is estimated that $20-30 \%$ of women have suffering menorrhagia problems in the reproductive age (15 - 40) [2]. The prevalence increases with age, peaking just before menopause. Some studies suggest that among women with normal bleeding patterns the prevalence of simple and complex hyperplasia is $0.5-5 \%$ and the prevalence of atypical endometrial hyperplasia or carcinoma is less than 1\% [4]. Estrogen and progesterone the two main hormones bring about their physiological and pathological effects through receptors namely Estrogen receptor (ER) and Progesterone receptor (PR). These receptors belong to the steroid receptor family and hence are found in the nuclear membrane of the endometrial cells. These receptors are closely interlinked and are mutually important for each other's regulation and expression. Hence by knowing the expression and distribution of these steroid receptors newer hormonal therapeutic options can be explored. Therapy with hormones is well established in cases of breast carcinomas and to some extent in endometrial carcinoma. Lack of documentation of receptor status in cases with endometrial hyperplasia which has now increased due to our life style changes is the lacuna which has resulted in the limited use of this therapy in these patients [3].

Hence there is enough literature to support the hormonal therapy in breast carcinoma and endometrial carcinoma which is based on the principles of stimulation of hormone receptors, but similar literature is deficient in studies regarding hormonal therapy and receptor status in endometrial hyperplasia. This study is aimed to evaluate the morphology of endometrial hyperplasia with an attempt to associate the changes with the estrogen and progesterone receptor status using a specific diagnostic modality of Immunohistochemistry, which will open up new possibilities in less invasive management of this condition especially in young women.

\section{Materials and Methods}

A cross sectional study was conducted in the Department of Phathology, Tertiary health care center, Puducherry. A total of 100 specimens of all endometrial curetting and hysterectomy were included in the study to diagnose an endometrial hyperplasia and were then subjected to immunohistochemistry studies for presence of estrogen (ER) and progesterone receptors (PR) status. In over a period of 2019 to 2021, Ethical clearance was taken from the Institutional Ethical Committee before start of the study (IEC Code No:30/2019). In this study all endometrial curettings and hysterectomy specimens diagnosed as endometrial hyperplasia irrespective of age and myometrial lesions were retrieved and included in the study. Cases diagnosed as endometrial carcinoma, chronic endometritis, crumbled endometrium, shedding endometrium, endometrial polyps and predominantly hemorrhagic samples were excluded from the study. The samples were subjected to routine histopathological examination in the Pathology Department with sections stained with Hematoxyllin and Eosin stains.

\section{Interpretation of stain}

Presence of brown color staining in the antigen binding site is considered positive. In our study the presence of brown staining in the nuclear membrane of the glandular epithelial and the stromal cells was considered positive. A tissue section from the normal endometrium was taken as positive controls and presence of brown staining in the nucleus was confirmed. Staining was scored using a semi-quantitative scoring system.

\section{H score system}

This score is a composite score of both the intensity of staining and the percentage of positively stained cells. An area of highest staining in each slide under oil immersion (100x) was designated as hot spot and a total of 500 cells was counted and was graded based on the intensity as follows [5].

The percentage of positively stained cells was done by two independent observers and rule out observer bias. The $\mathrm{H}$ score was then calculated by multiplying the percentage of stained cells (Pi) with each grade of intensity (i) and the sum of these values was calculated and recorded as that tissue's $\mathrm{H}$ score. The normal range of values was $0-300$. The positivity of the values was grouped (HScore).

\section{Statistical analysis}

Percentage of specimens with endometrial hyperplasia that were diagnosed in the Pathology Department of Pathology, in reproductive and perimenopausal and postmenopausal age group were documented. Also the intensity of estrogen and progesterone 
receptor activity was correlated with the extent of hyperplasia and independent $t$ test was applied to determine the level of significance and the strength of association was calculated.

\section{Results and Observations}

A total number of 100 case sample collected from subjects of endometrial curettings and hysterectomy diagnosed as endometrial hyperplasia of any type across all ages was taken for the study. The age group of patients was stratified into three groups.
Among the retrieved samples for the study 75 was endometrial curettings (C) and 25 was hysterectomy (H) specimens diagnosed with various types of endometrial hyperplasia. Comparison was made between the presenting clinical diagnosis and age group which reiterated the fact that DUB (75\%) was the most common diagnosis in the women of reproductive age group and among the perimenopausal age group the frequency of DUB was $17 \%$, making it the most common clinical presentation (Table1) and (Figure 1). The sample was evaluated for the histopathological diagnosis based on the WHO classification and the frequency of cases.

\begin{tabular}{|l|c|c|c|c|}
\hline \multirow{2}{*}{ Hormones } & Histopath diagnosis & $\begin{array}{c}\text { Mean and } \\
\text { SD }\end{array}$ & $\begin{array}{c}\text { No. of } \\
\text { Cases }\end{array}$ & P-value \\
\hline \multirow{4}{*}{$\begin{array}{l}\text { Progesterone Receptor } \\
\text { gland }\end{array}$} & Complex hyperplasia without atypia (CH) & 270 & 1 & NA \\
\cline { 2 - 5 } & Simple hyperplasia without atypia (SH) & $188.9 \pm 103.1$ & 83 & $<.001$ \\
\cline { 2 - 5 } & Simple hyperplasia with atypia (SHA) & $135 \pm 112.5$ & 8 & 0.037 \\
\hline \multirow{3}{*}{$\begin{array}{l}\text { Estrogen } \\
\text { Receptor stroma }\end{array}$} & Complex hyperplasia without atypia (CH) & 220 & 1 & NA \\
\cline { 2 - 5 } & Simple hyperplasia without atypia (SH) & $150.2 \pm 85.6$ & 83 & $<.001$ \\
\cline { 2 - 5 } & Simple hyperplasia with atypia (SHA) & $85.6 \pm 95.4$ & 8 & 0.013 \\
\hline \multirow{3}{*}{$\begin{array}{l}\text { Progesterone Receptor } \\
\text { stroma }\end{array}$} & Complex hyperplasia without atypia (CH) & 240 & 1 & NA \\
\cline { 2 - 5 } & Simple hyperplasia without atypia (SH) & $153.9 \pm 82.7$ & 83 & $<.001$ \\
\cline { 2 - 5 } & Simple hyperplasia with atypia (SHA) & $110 \pm 98.7$ & 8 & 0.087 \\
\hline \multirow{3}{*}{$\begin{array}{l}\text { Estrogen Receptor } \\
\text { gland }\end{array}$} & Complex hyperplasia without atypia (CH) & 200 & 1 & NA \\
\cline { 2 - 5 } & Simple hyperplasia without atypia (SH) & $194.2 \pm 94.4$ & 83 & $<.001$ \\
\cline { 2 - 5 } & Simple hyperplasia with atypia (SHA) & $105 \pm 109.7$ & 8 & 0.002 \\
\hline
\end{tabular}

Table 1: Comparison of stroma and gland Statistical significance of stroma and gland: Simple Hyperplasia without Atypia (SH); Simple Hyperplasia with Atypia (SHA); Complex Hyperplasia without Atypia (CH).

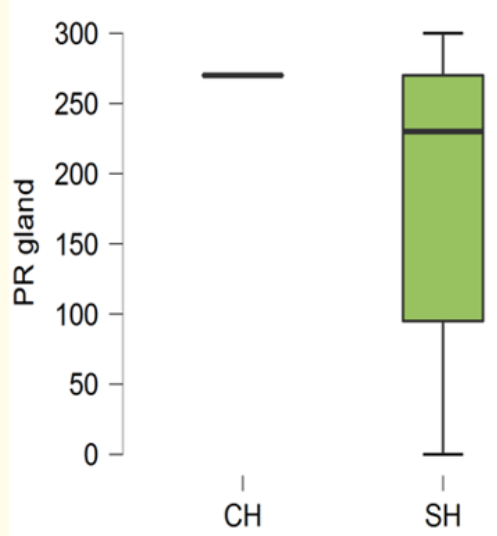

histopath diagnosis

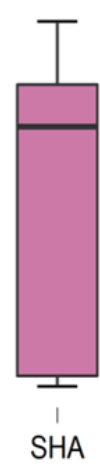

SHA

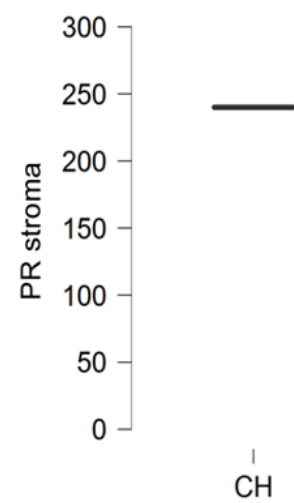

$\stackrel{\mathrm{C}}{\mathrm{CH}}$
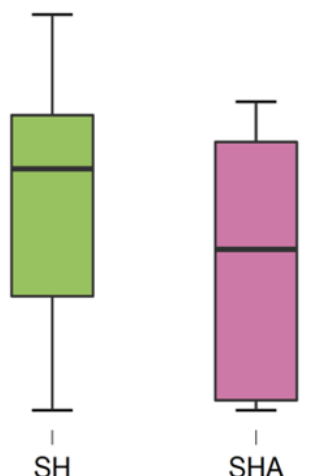

histopath diagnosis 

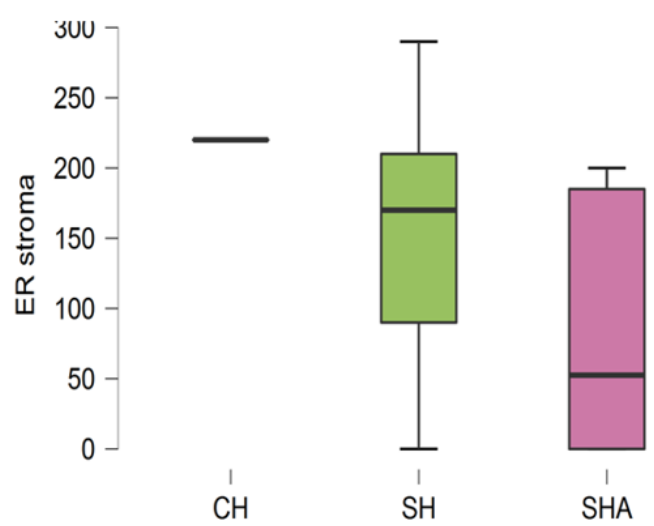

histopath diagnosis

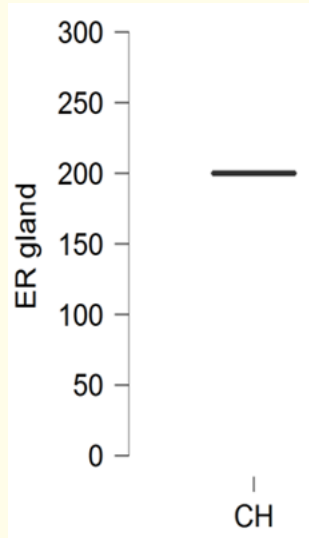

Figure 1: Histopathological patterns of cases with H score stroma and gland in Comparison of Estrogen Receptor (ER) and Progesterone Receptor (PR).: Simple Hyperplasia without Atypia (SH); Simple Hyperplasia with Atypia (SHA); Complex Hyperplasia without Atypia (CH).

Among the 100 cases the subtype of simple hyperplasia without atypia (SH) accounted for $90 \%$ of the cases followed by simple hyperplasia with atypia (SHA) seen in 9 cases. Only one case of complex hyperplasia without atypia $(\mathrm{CH})$ was received and no cases of Complex hyperplasia without atypia were diagnosed during the study period. Comparison of estrogen receptor status (H scores) both in gland and stroma with different types of hyperplasia, An Immunohistochemical study was performed to locate and tabulate the estrogen receptor and the progesterone receptor status.
Positive staining of both these receptors was seen as fine granular brown positivity in the nuclear membrane of the cells of glands and stroma. An area of highest staining in each slide was designated as hot spot and a total of 500 cells was counted and was graded based on the intensity as Absent- 0 , weak-1, distinct- 2 and intense-3. This semi quantitative assay was performed in both the glandular epithelial cells and the stromal cells for both the ER and PR receptors. Among the cells the vascular smooth muscle cells and the endothelial cells was consistently negative. Myometrium showed positivity in many cases. In both these tables only the mean receptor scores are calculated for the case of complex hyperplasia because its number was only 1 case. These ranges were then considered and the frequency of staining in different cases of hyperplasia was documented for comparison.

But this sole value cannot be considered because there was only one case of $\mathrm{CH}$ and no cases of CHA in the sample studied. In our cases the statistical significance of receptor status with histopathological subtype was considered which did not show any significant association (Figure 2). The statistical comparison was not possible because the frequency of cases in each subtype were not similar. The aim of this study was to determine and document the association of ER and PR receptors in hyperplastic endometrium and to compare the receptor status in different subtypes of endometrial hyperplasia. This has not been documented to the best of our knowledge. In this study we have found that the intense mean intensity of PR (G) was slightly higher than its counterpart in cases of hyperplastic endometrium. Similarly, the stromal staining of these receptors with respect to its histopathological subtype was documented as follows.

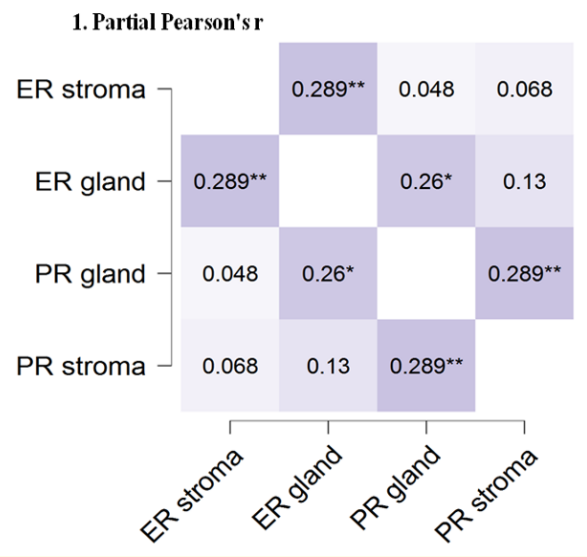




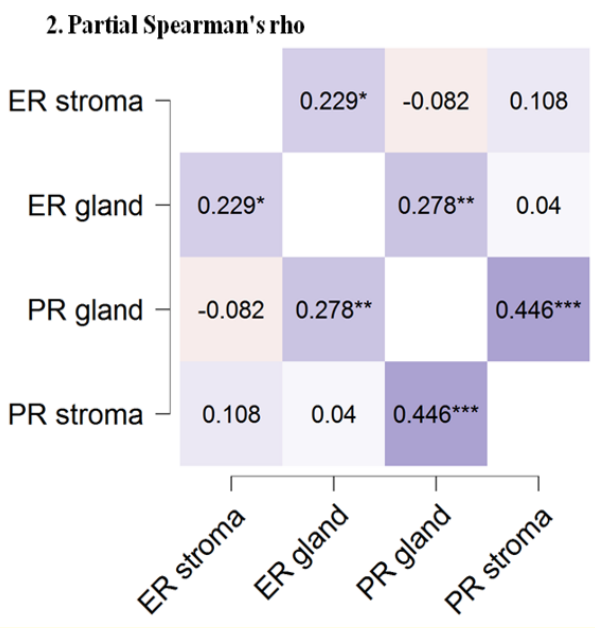

Figure 2: Statistical significance in Distribution patterns of stroma and gland in Comparison of Estrogen Receptor (ER) and

Progesterone Receptor (PR).

Percentage of specimens with endometrial hyperplasia that was diagnosed in the reproductive and perimenopausal and postmenopausal age group was documented. Also, the intensity of estrogen and progesterone receptor activity was correlated with the extent of hyperplasia and independent $t$ test was applied to determine the level of significance, but not statistical significance was noted with the ER and PR status in the stromal cells in comparison with individual subtypes of endometrial hyperplasia. Intensely stained cases with $\mathrm{H}$ score $>200$ was taken and compared which showed PR intensity slightly higher than the ER intensity in both Gland and stromal cells.

\section{Discussion}

Endometrial hyperplasia, is the most important cause for bleeding in patients with dysfunctional uterine bleeding (DUB) and more than half of these patients who are in the reproductive age group undergo hysterectomy as there are limited medical therapeutic options. The success of hormonal therapy with steroid hormones such as estrogen and progesterone depend on the activity and the availability of specific receptors in the target tissue. Altered morphology and the receptor levels in cases of endometrial hyperplasia suggest and prove estrogen over activity as the main etiology in these patients. Detecting and analyzing these receptor statuses can be done using various methods like tissue homogenization and bio- chemical methods but are very time consuming and are not accurate hence less reliable [6]. Immunohistochemistry has now come a long way in overcoming these problems and it is very accurate as the visualization of receptors in individual cells in a tissue is possible. Most receptor status studies done on normal endometrium and in neoplastic endometrium exist in literature but there are only limited resources when it comes to receptor status in hyperplastic endometrium.

This study was done on endometrial tissue diagnosed as endometrial hyperplasia and the Estrogen receptor (ER), Progesterone Receptor status (PR) in those cases were done using specific monoclonal antibodies against these receptors. Since upto $75 \%$ of cases were diagnosed clinically to have dysfunctional uterine bleeding, the mean age of presentation was calculated and found to be 38 years which was similar to the studies done by Gleason., et al. and S Chakraborthy., et al. [7,8].

The incidence of simple hyperplasia in the patients diagnosed with DUB(92\%) was similar to the studies done by Takreem., et $a l$. and Israel., et al. showing that hyperplastic endometrium was one of the commonest etiologies for DUB $[9,10]$. Use of immunohistochemistry using monoclonal antibodies in detecting the expression of a protein in tissue specimen has been validated by previous studies. The nuclear localization of estrogen and progesterone receptors has also been established with various studies $[10,11]$. $\mathrm{H}$ scores system is a semi-quantitative scoring system which is widely used in scoring hormonal status in breast carcinoma and to some extent in endometrial carcinoma [3]. Its accuracy has been compared quantitatively with other biochemical assays in previous studies and has been found sensitive $[12,13]$. Hence this system of scoring which is a composite score of percentage of positive cells and intensity is employed in this study.

Previous receptor status studies done in normal endometrium by various authors have established that in cases of DUB there was an increasing trend in both ER and PR expression in proliferative phase and decreasing trend during the secretory phase when compared with endometrium in asymptomatic patients [8,14]. This trend supports the theory that, estrogen hormone stimulates the expression of both the receptors during the proliferative phase and the progesterone will suppress both receptors during secretory phase. Studies done on cases diagnosed with DUB have shown that increased and prolonged proliferation of endometrium occurs 
through the hormonal receptors, which then transforms into unopposed action of estrogen which thus leads to hyperplasia [7,9]. Nyholm., et al. and Bergeron., et al. In their studies reported that the levels of ER and PR were high among the cases of simple hyperplasia without atypia $(\mathrm{SH})$ and complex hyperplasia without atypia $(\mathrm{CH})$ and there is progressive loss of these receptors in simple hyperplasia with atypia (SHA) and complex hyperplasia with atypia (CHA) $[11,15]$. In our study we found that the mean H score values of ER in gland and stroma ER(G) and ER(S) and PR in stroma PR(S) were high in cases of $\mathrm{SH}$ and $\mathrm{CH}$. However PR(S) and PR(G) was high in cases of SHA.

Hence this study has shown that progesterone receptor positivity is marginally higher than the estrogen receptor status which is favorable for trying medical management in cases of simple hyperplasia. Endometrial hyperplasia especially simple hyperplasia without atypia mostly undergoes spontaneous regression in patients and for most of them curettage alone is sufficient as it rarely progresses to endometrial malignancy $[7,16]$. According to Reed., et al. Previous studies have clearly stated that this subtype is the commonest among endometrial hyperplasia [17]. Complex hyperplasia and atypical hyperplasia be it SHA or CHA have a minimal risk of malignant transformation, hence the protocol mandates that these patients be treated with progestins and then followed up with hysterectomy if there is no resolution $[2,4,18]$.

Reed., et al. In his study noted that regression was seen in two thirds of his study group after administration of progesterone therapy using megesterol acetate (MEGA), medroxyprogesterone acetate (MPA), and norethindrone acetate (NETA) [17]. This study does not document the hormone receptor status of the patients. Newer treatment options using progesterone receptor modulators are also being used for the medical management of these cases.

\section{Conclusion}

Dysfunctional uterine bleeding has become the leading presenting complaint in any gynecology. Previously more common in perimenopausal age group it has now affected even the women of reproductive age group (18-30 years). Endometrial hyperplasia is the commonest etiology for the patients with DUB occurring in the background setting of estrogen excess. The progression of endometrial hyperplasia is dependent on the estrogen and progesterone hormonal receptor status of the endometrium. Immunohistochemical estimation of estrogen and progesterone receptors is a sensitive and reliable method as it determines the localization at a cellular level. From this study we conclude that simple hyperplasia without atypia is the most common subtype which has the least risk of malignant progression. The intensity of progesterone receptor (PR) is more than its counterpart which is a favorable advantage to consider progestin therapy. This study, we hope will open up new strategies in medical management of DUB and can replace the much common surgical management and feasibility of minimally invasive mode of management which can be useful for these patients.

\section{Acknowledgement}

We are acknowledging the participants of this study.

\section{Conflict of Interest}

The authors declare that they have no conflicts of interest.

\section{Ethical Approval}

The study was approved by the Institutional Human Ethics Committee (IEC Code No: 30/2019).

\section{Informed Consent}

Informed consent form was obtained from all the participants in the study group.

\section{Funding}

Nil.

\section{Bibliography}

1. Robbins S Kumar., et al. "pathologic basis of disease. $8^{\text {th" }}$ Saunders Philadelphia, PA (2010).

2. Palter S and Olive D. "Reproductive physiology". Williams and Wilkins, Baltimore (1996).

3. Wang C., et al. "Estrogen Receptor, Progesterone Receptor, and HER2 Receptor Markers in Endometrial Cancer". Journal of Cancer 11.7 (2020): 1693-1701.

4. Haines M., et al. "Haines and Taylor Obstetrical and Gynaecological Pathology". Churchill Livingstone (2003).

5. Fedchenko $\mathrm{N}$ and Reifenrath J. "Different approaches for interpretation and reporting of immunohistochemistry analysis results in the bone tissue-a review". Diagnostic Pathology 9.1 (2014): 1-12. 
6. Reed SD., et al. "Progestin therapy of complex endometrial hyperplasia with and without atypia". Obstetrics and Gynecology 113.3 (2009): 655.

7. Chakraborty S., et al. "Endometrial hormone receptors in women with dysfunctional uterine bleeding". Archives of Gynecology and Obstetrics 272.1 (2005): 17-22.

8. Gleeson N., et al. "Cyclical variation in endometrial oestrogen and progesterone receptors in women with normal menstruation and dysfunctional uterine bleeding". European Journal of Obstetrics and Gynecology and Reproductive Biology 48.3 (1993): 207-214.

9. Israel R., et al. "Mechanisms of normal and dysfunctional uterine bleeding". Clinical Obstetrics and Gynecology 13.2 (1970): 388-399.

10. Takreem A., et al. "Incidence of endometrial hyperplasia in 100 cases presenting with polymenorrhagia/menorrhagia in perimenupausal women". Journal of Ayub Medical College Abbottabad 21.2 (2009): 60-63.

11. Bergeron C., et al. "Immunocytochemical study of progesterone receptors in hyperplastic and neoplastic endometrial tissues". Cancer Research 48.21 (1988): 6132-6136.

12. Mylonas I., et al. "Immunohistochemical labelling of steroid receptors in normal and malignant human endometrium". Acta Histochemica 111.4 (2009): 350-360.

13. Soper JT., et al. "Estrogen and progesterone receptor content of endometrial carcinomas: comparison of total tissue versus cancer component analysis". Gynecologic Oncology 36.3 (1990): 363-368.

14. Mutch DG., et al. "Endometrial adenocarcinoma estrogen receptor content: association of clinicopathologic features with immunohistochemical analysis compared with standard biochemical methods". American Journal of Obstetrics and Gynecology 157.4 (1987): 924-931.

15. Nyholm HC., et al. "Biochemical and immunohistochemical estrogen and progesterone receptors in adenomatous hyperplasia and endometrial carcinoma: correlations with stage and other clinicopathologic features". American Journal of Obstetrics and Gynecology 167.5 (1992): 1334-1342.

16. Figueroa-Casas PR., et al. "Reversal by medical treatment of endometrial hyperplasia caused by estrogen replacement therapy". Menopause 8.6 (2001): 420-423.
17. Reed SD., et al. "Complex hyperplasia with and without atypia: clinical outcomes and implications of progestin therapy". $O b$ stetrics and Gynecology 116.2-1 (2010): 365-373.

18. Hernandez E. "ACOG Practice Bulletin number 65: management of endometrial cancer". Obstetrics and Gynecology 107.4 (2006): 952.

\section{Assets from publication with us}

- Prompt Acknowledgement after receiving the article

- Thorough Double blinded peer review

- Rapid Publication

- Issue of Publication Certificate

- High visibility of your Published work

Website: www.actascientific.com/

Submit Article: www.actascientific.com/submission.php

Email us: editor@actascientific.com

Contact us: +919182824667 